\title{
Micro-Manufacturing: Research, Technology Outcomes and Development Issues
}

\author{
Y. Qin, A. Brockett, Y. Ma, A. Razali, J. Zhao, C. Harrison, W. Pan, X. Dai and D. Loziak \\ DMEM, The University of Strathclyde, Glasgow, G1 1XJ UK \\ Tel: 0044141548 3130; Fax:0044 1415527986
}

\begin{abstract}
Besides continuing effort in developing MEMS-based manufacturing techniques, latest effort in Micro-manufacturing is also in Non-MEMS-based manufacturing. Research and technological development (RTD) in this field is encouraged by the increased demand on micro-components as well as promised development in the scaling down of the traditional macro-manufacturing processes for micro-length-scale manufacturing. This paper highlights some EU funded research activities in micro/nano-manufacturing, and gives examples of the latest development in micro-manufacturing methods/techniques, process chains, hybridprocesses, manufacturing equipment and supporting technologies/device, etc., which is followed by a summary of the achievements of the EU MASMICRO project. Finally, concluding remarks are given, which raise several issues concerning further development in micro-manufacturing.
\end{abstract}

Keywords: Micro-Product, Micro-Manufacturing, Manufacturing System

\section{Introduction}

There are various techniques which can be used for the manufacture of micro-products. MEMSbased manufacturing involves, largely, techniques such as photolithography, chemical-etching, plating, LIGA, laser fabrication, etc. while non-MEMS-based manufacturing often involves techniques such as mechanical machining, EDM, laser-cutting/patterning/drilling, embossing, injection-moulding, forging, extrusion, stamping, etc. Regarding materials to be dealt with, micromanufacturing is, sometimes, also categorised as silicon-based manufacturing and non-siliconematerial-based manufacturing. The purpose of differentiating these may be to emphasise the importance of the latter as an emerging field. 
For traditional, MEMS-based manufacturing practicians, micro-manufacturing may not be new, as manufacturing various MEMS and micro-systems has been undertaken by industry for many years, which has also been performed in volume-production scales. Needs of developing new, multifunction and multi-material micro-products/systems as well as improving manufacturing efficiency due to the increased competition have, however, raised new challenges to the manufacturing. This is not only because the manufacturing will have to deal with much wider ranges of the materials which cannot be coped with the traditional MEMS-based manufacturing techniques alone but also because scaling down the processes, tools and machinery from conventional ones is not a easy task (such as mechanical and thermal cutting and forming to cope the needs of achieving much small dimensions and intricate geometries). From this sense, emerging micro-manufacturing techniques often refer to non-silicone-materials-based and even non-MEMS-based manufacturing. No matter which focus is addressed, there is common recognition that micro-manufacturing should be effected with use of miniature manufacturing equipment, which, presently, is a major part of the RTD in micro-manufacturing.

Transforming conventional macro-manufacturing to micro-manufacturing is feasible and a lot of successful cases have proved it. However, these might have been achieved with high costs. Significant efforts are still needed to better understand material behaviours at micro/nano-scales, process capabilities of certain manufacturing methods/processes, and even manufacturing operational philosophy. New strategies are needed for tool and machinery design. Advance is needed in handling and inspection for dealing small length-scale manufacturing. Manufacturing process chains need to be optimised to ensure "optimal" solutions, etc. This paper intends to address some of these issues, with particular attention to highlight recent efforts from the EU MASMICRO project.

\section{EU Funded Research Activities in Micro-Manufacturing}

The European Commission has invested heavily in the research in micro- and nano-manufacturing [1-3], and EU's leading roles in this field are evident in the WTEC report [4] which emphasised the EU's efforts and their significance. The trend has been obviously enhanced since the EU FP6 NMP programme started. In the manufacturing field, this was largely due to set-up of some flagship projects [1-3], such as MASMICRO, 4M, Launch-Micro, Production4 $\mu$, EUPASS, Hydromel, HYTI, NANOSAFE2, Manudirect, Napolyde, PRONANO, NaPa, CHARPAN, NANOIMPRINT, NanoCMM, etc. The projects covered the areas such as Micro-manufacturing (mass-manufacture of micro-products, multi-materials micro-manufacturing technologies and applications, direct 
manufacturing by laser sintering, production technologies for micro-products with glass materials, transforming traditional SME industry to micro-manufacturing, etc.); Precision manufacturing (ultra-precision machining and assembly systems, hybrid ultra precision manufacturing process based on positional- and self-assembly, direct ultra-precision manufacturing); Nano-manufacturing (safe production and use of nanomaterials, nano-structured polymer deposition processes for mass production, nanopatterning (emerging methods), production of massively parallel intelligent cantilevers, charged particle nanotechnologies, etc.); and Metrology (Coordinate metrology for Micro and Nano components production, etc.). These efforts have enabled the EU to ensure its leading position in these individual areas. For example, MASMICRO developed a new, integrated manufacturing facility which enables mass-manufacture of micro-products with new forming and machining techniques. This initiative also brought together the development in all related fields such as design, analysis, materials, testing, tooling, machinery, handling, assembly, inspection and manufacturing automation. $\mathbf{4 M}$ assembled a group of excellent researchers in micro-manufacturing and related fields through this network. It particularly covered various material-processing processes such as metals, polymers, ceramics and glass. One of the focuses was to optimise the micro-manufacturing chains with a view to enabling better manufacturing capability, quality and efficiency. Production $4 \boldsymbol{\mu}$ project aimed the investigation and application/verification of radical new production concepts, utilising new methodologies and standards as well as radical new manufacturing processes and automation technologies to transfer lab-scale prototype production into industrial scale production of $\mu$-glass-components. HYDROMEL aimed at developing a new versatile $3 \mathrm{D}$ automated production system with a positioning accuracy of $100 \mathrm{~nm}$ for complex micro-devices with combination of positional assembly and self-assembly. Similarly, EUPASS aimed to develop affordable, cost effective and sustainable ultra-precision manufacturing solutions by offering rapidly deployable ultra-precision assembly services on demand. Napa conducted the research in three technology strands: Nanoimprint lithography, Soft lithography \& self-assembly and MEMS-based Nanopatterning. Its aim was to meet nanoscale precision requirements together with certain mass production capability, which may open the door for new-generation, high added value products. NAPOLYDE developed new technologies for polymer or polymer-like films deposition at nano-scale precision supporting mass production and environmental friendly requirements. The development included robust and scalable deposition technologies, measurement instruments, design tools, scale-up methodologies and know-how. Manudirect was to provide a novel platform for the manufacture, through sinterised laser of hi-resolutions with metals and ceramics materials. The future resolution of the system will be below the 50 microns and it will allow the manufacture of pieces with different compositions in its different zones, through the manufacture in a single step. Latest development also includes HYTI project which develops 
Nanoimprint, Micro PIM and Hybrid processing technologies for emerging multi material based micro devices.

Other relevant projects also generated significant results which are of interest to micro/nanomanufacturing, such as: Eurotooling21 (EU FP6 SME-IP, tooling production for injection moulding, precision and micro-manufacturing); RAMA3DP (EU FP6 SME-IP, Improving three dimensional printing for rapid manufacturing of products with a view to solving the mechanical strength, reproducibility, accuracy, and colour drawbacks of current rapid prototyping methods); CUSTOM-FIT (Development of a knowledge-based manufacturing system with integration of Rapid Manufacturing, IST and Material Science to improve the quality of life through custom fit products. The key technologies being explored include High viscosity jetting, Metal printing, Multiple deflection continuous jetting processes, "Upside down" 3D printing processes, etc.); and METAL-PRINT (FP6-SME, development of a new flexible manufacturing technique for highly detailed, custom made metallic products by Metal Inkjet Printing).

Past completed projects [3] such as ARMMS (BRITE/EURAM 3, Network for Agile reconfigurable manufacturing machinery systems); CLAW (BRITE/EURAM project, Clean and low distortion accurate welding for micro assembly); TOPAS (BRITE/EURAM 3 Project, Tool technology for high accuracy micro part stamping); FLAME project (GROWTH project, Flexible laser-assisted micro-engineering) aimed at the development of a novel, compact, laser based machine tool with high flexibility concerning the variety of materials and geometry, reached by the different laser types and realisation of a flexible strategy. This type of machine allows the economic manufacturing of prototypes and small batch sizes of high precision micro-components. Another project in "The integration of computer modelling, mould design \& the LIGA process for microinjection moulding of plastic parts", PURE (Growth project, Patterning by UV laser material removal) was to develop and construct a laser based machining centre, that combines the latest development in micro-machining, scanner technology and UV-laser technology. The association of UV-laser technology with a scanning system instead of a traditional linear axis positioning system can increase speed, precision, flexibility and accuracy of the laser material processing. By using scanning devices, UV-lasers and improved ablation strategies, a more accurate local ablation can be achieved.

Other relevant projects included ROBOSEM, NANOHAND in handling, MICROMAC for MicroEDM, LAMAR for Laser-assisted chemical micro-machining and replication, PATENT for Design for micro and nano manufacturing, JOITEC for lead free joining for micro electronics and 
microsystem technology device.

\section{The State-of-the-Art of the Research}

\subsection{Manufacturing Methods/Processes}

Both conventional and non-conventional methods have been used to manufacture micro-products [5]. There have also been newly emerging methods such as hybrid manufacturing methods/processes. The following texts highlight some examples of the recent development of micro-manufacturing methods/processes.

Micro-Mechanical-Cutting is a technology that has been widely investigated in the field of precision engineering. Micro-machining may be seen as an ultra-precision material removal process which is able to achieve micro-form-accuracy and nano-meters finish [6]. From precisionmachining to micro-machining, there are still some challenging issues to be addressed such as predictability, producibility and productivity in micro-scale manufacturing [7]. It is difficult to achieve complex 3D, intricate micro-features/components with mechanical micromachining, although it is still a powerful technology in developing micro-components for various systems such as those operating on electronic, mechanical, fluidic, optical, and radiative signals [8], e.g. the systems for micro-instrumentation, inertial sensing, biomedical devices, wireless communication, high-density data storage, etc. as well as producing dies and moulds for other manufacturing processes such as for micro-forming and injection moulding [6-8].

Due to the working principle of removing chips by mechanical forces, significant efforts have been devoted to the improvement of the precision of the machine tools and the development of errorcompensation methods to ensure the required machine-tool-workpiece system precision. Main issues still being addressed include understanding of chip formation mechanisms and micromachining mechanics, machine-tool design with "optimal" dynamics stiffness, optimal cutter geometry/materials and motion control, in-process inspection with high resolution metrology, etc. [6-7]. Bench-top machine-tool designs have now become a trend showing that the machine development is being shifted from large scale, ultra-high precision machine strcuture designs to small/miniature structure and low cost system designs. Ultra-high precision and high-speed spindle design is another subject attracting many researchers and industries' interest. Diamond cutting tools, tools with nanocrystalline diamond coating [9], etc. are also widely studied. 
Micro-EDM: Electro-physical and chemical micromachining processes play important roles in micro-manufacturing due to their special material removal mechanisms [10]. Electrical-DischargeMachining (EDM) is especially suitable for manufacturing micro-components due to its thermal material removal mechanism, which allows an almost process-force free machining independently of the mechanical properties of the processed material. High precision Micro-EDM can process functional materials like hardened steel, cemented carbide and electrically conductive ceramics with sub-micron precision [10]. Its applications are far beyond dies/moulds fabrication, such as microgears, micro-fluidic devices, medical implants, etc. Besides the miniaturization of the tool electrodes, compared to conventional EDM, minimising the discharge energy (e.g. $\left.\mathrm{W}_{\mathrm{e}}=0.1 \mu \mathrm{J}\right)$ to allow only a very small material-removal at one single discharge, and hence, extremely small gap width (e.g. 1.5 to $5 \mu \mathrm{m}$ [11]). To achieve a reasonable material removal rate, spark generators which are able to produce extremely high impulse frequencies are needed. Some generators for microelectrical discharge machining are capable of impulse frequencies up to $10 \mathrm{MHz}$ [12]. In a recent publication [13], a series of factors which could contribute to the component-form errors in microEDM were reviewed, which may be used as a guidance for planning the process within the expected tolerances.

Micro Electrochemical Machining: ECM is another popular choice for making micro-parts, due to less effort needed for handling during the ECM, easy control of the process, being relatively simple for the machine design/set-up (CNC possible) and capable of processing various materials, including high-strength materials. Other attractive characteristics include burr-free surface produced, no thermal damages, no distortion of part and no tool-wear. The issues often investigated with reference to micro-manufacturing applications include controlling material removal, machining accuracy, power supply, design and development of micro-tools, roles of inter-electrode gap and electrolyte, etc. [14]. High surface roughness, relatively poor fatigue properties, difficulty to make sharp corners, etc. are some negative aspects to be taken into account when the process is to be considered for micro-manufacturing. For micro-machining, masks may be used (one-side or two sides possible) for making finer geometry. For precision manufacturing, a pulsed power of relatively short duration (about $1 \mathrm{~ms}$ ) may be used, which enables shorter inter-electrode gaps $(<50 \mu \mathrm{m})$ to be utilised. The small gaps with good process control can yield accuracies of $0.005 \mathrm{~mm}$ and surface roughness of $\mathrm{Ra} 0.03 \mu \mathrm{m}$ [15]. A recent report stated that accuracies of the order of \pm 1 $\mu \mathrm{m}$ on $50 \mu \mathrm{m}$ is also achievable [14].

Laser Technology: Laser technology has been qualified as an efficient micro-manufacturing technology because of its high lateral resolution with the minimized focus-ability down to a few 
microns or even smaller, low heat input and high flexibility. One major advantage is its capability of processing various materials which are increasingly needed for manufacturing micro-products. Some examples for laser applications are micro-cutting, micro-drilling, micro-welding, soldering, selective bonding of silicon and glass, micro structuring and forming [16]. Femtosecond laser micromachining is a new approach emerging in MEMS area in recent years, and some promising results have been shown in micromachining and micro-system applications, including that in industrial material processing, biomedicine, photonics and semiconductors [17]. The ultra-fast, or ultra-short, laser means that the laser pulse has a duration that is somewhat less than about 10 picoseconds [18]. It utilizes the ultrashort laser pulse properties to achieve an unprecedented degree of control in sculpting the desired microstructures internal to the materials without collateral damage to the surroundings. It has been proven that micro-structuring with femtosecond laser pulses is an excellent tool for free design micro-fabrication of almost all kinds of materials [19]. With the filament, spatially scanning and other methods, many types of optical microstructures (including 3D) such as optical memory, waveguides, gratings, couplers and photonic crystals, were produced successfully inside a wide variety of transparent materials of solid state and also liquid state [19]. Although further applications have been reported, this technology is still not matured and not understood very well [17].

Micro-forming: Micro-products may be produced with plastic forming technologies [20-25], i.e. micro-forming. Various forming/forging configurations are possible such as forging, extrusion, stamping, bending, hydro-expansion, superplastic forming, etc. These may be achievable by effective scaling down of the conventional configurations, tools and even machines with extra cares [20]. The forming of small metal-parts, or miniature-parts, may not be new. However, challenges do arise when the sizes/features reduce to such as to tens or hundreds of microns, or the precision requirements for macro/miniature-parts reduce to such as less than a few microns. Nevertheless, metal-forming offers some attractive characteristics that are superior to those of other processes, for example, machining and chemical-etching, considering such features as higher production-rates, better material integrity, less waste, lower manufacturing costs, etc. Therefore, micro-forming could be a better option in the mass-manufacture of miniature/micro-parts at reduced cost, if current technology is advanced further and a proper manufacturing facility is developed. Fundamental issues concerning micro-metal-forming have been studied intensively over the last 10 years [21, 23]. Major issues examined were related to understanding of material deformation mechanisms and material/tool interfacial conditions, materials property characterisation, process modelling and analysis, qualification of forming limits, process design optimisation, etc., with emphasis on the related size effects. Studying the research reported previously and recent research conducted in- 
house resulted in the following observations:

(i) Conventional metal-forming process-configurations such as forging, extrusion, stamping, coining, deep drawing, etc. may be equally used for the forming of miniature/micro-parts; process capabilities are likely to be constrained more, due to additional material, interfacial and tooling considerations in micro-forming.

(ii) The types of the materials which could be formable at micro-levels are prescribed more significantly than for forming at macro-levels by the micro-structures and grain-boundary properties of the materials. The forming limits for these materials are, therefore, somewhat different, compared to those for the forming of macro-parts.

(iii) Size-effects may exist in material property and tool-material interfacial property characterisation, depending largely on the micro-structures of the materials, which leads to the requirement of the definition of these parameters with reference to the actual materials and interfaces to be used.

(iv) Besides the miniature/micro-parts already produced in industry, some micro-parts with much smaller scales have been produced in the laboratory, which have shown the feasibility of the technology. The precision of the manufacturing needs to be further addressed.

Machines, forming-tools and handling devices are critical in the industrial applications of microforming technology. Some traditional forming-machine designs may be scaled down for microforming needs, as long as the machines are able to cooperate with the use of micro-tools of acceptable quality and efficiency. However, more particular considerations will have to be incorporated into machine design to meet engineering applications requirements, e.g. greater precision, handling of micro-parts/materials with higher rates and positional precision.

Laser Assisted Forming: Heating has been widely used for assisting in forming processes, largely due to the improved material follow-ability and reduced strength at elevated temperature. Therefore, the forming processes can be easier and forming loading can be reduced. The influence on the forming tools is a mixture of the reduction of the forming pressures and superimposition of thermal loads from the heating. Introducing the heating helps to process materials with higher strength and/or extend forming ability including component/part-forms and dimensions or aspect ratios. Heating with laser is especially effective for the forming of sheet metals or thin sections from bulk materials. With selectively applying the laser beam to the focused area(s), the laser can be used in processes such as bending, deep drawing, stamping, can-extrusion, tube forming, etc. [16, 26] [27, 28]. Transparent tools made of sapphire permit the guidance of the laser radiation directly onto the workpiece within the closed tool-set during the processes. This means no separated preheating step 
needed and the avoidance of an extended processing time.

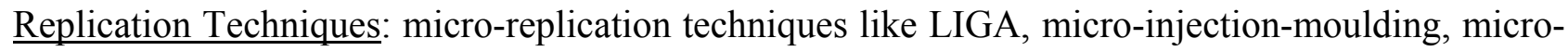
casting and micro-embossing are seen as solutions to low cost, mass-production of microcomponents/features, and reel-to-reel UV embossing is a good example for mass-production. Materials that can be processed with replicating techniques include metals, glass, polymers, etc. Especially, embossing, moulding and casting are very effective for fabricating microstructures for optical elements/devices, which can produce high resolutions possibly in the nano-meter ranges with some dedicated configurations/set-ups, and these could allow the fabrication of complex micro-structures over large areas. Processes for gratings, holograms and diffractive foils are well established. Efforts are continually being made to extend the process capability such as increasing the aspect ratios of the microstructures; producing these in larger areas (such as replicating microstructures with optical functions with dimensions between $200 \mathrm{~nm}$ and $50 \mu \mathrm{m}$ on areas of up to half a square meter or more); combining embossing with other processes such as lithography, dry etching and thin-film coating, etc. Micro powder injection moulding ( $\mu \mathrm{PIM})$, is a potential low-cost mass fabrication process for manufacturing microstructures and micro-components [29]. It could be used for processing many different materials (e.g., ceramics and metals) for very complex geometries. For making small geometries, silicon-mould-inserts may be used, taking advantages of deep reactive ion etching. The processing parameters need to be carefully set in order to produce the required quality and small features. LIGA, an alternative micro-fabrication process combining such as deep X-ray lithography, plating-through-mask and moulding, enables the highly precise manufacture of high-aspect-ratio microstructures with large structural height ranging from hundreds to thousands of micrometers thickness [30] which are difficult to be achieved with other manufacturing techniques. Significant progress in MEMS manufacturing is largely due to introduction of the LIGA process. The Polymer LIGA process is especially suitable for massproduction.

Deposition Methods: Electroforming is a highly specialised use of electro-deposition for the manufacture of metal parts. The materials which can be processed include copper, nickel, iron or silver, thickness up to $16 \mathrm{~mm}$, dimensional tolerances up to $1 \mu \mathrm{m}$, and surface finishes of $0.05 \mu \mathrm{m}$ $\mathrm{Ra}$ [31]. The applications include tooling, mould-making, fabrication of MEMS directly. Physical and chemical depositions seem to be seen as effective methods of fabricating multi-material devices with no need to increase the process chain. Possible methods for micro-manufacturing include Laser-assisted Chemical Vapor Deposition (LCVD), Laser Guided Direct Write (LGDW) and Flow-Guided Direct write (FGDW), Shape Deposition Modelling (SDM), Localised 
Electrochemical Deposition, etc. [32]. For example, a similarity between the silicon-based MEMS methods and Shape Deposition Manufacturing (SDM) is that "both integrate additive and subtractive processes and use part and sacrificial materials to obtain functional structures" [33], while the latter is able to deal with more types of the materials. A micro rapid prototyping system was developed [33] which included micro-deposition, ultrasonic-based micro powder-feeding, dry powders cladding/sintering, laser micromachining (a laser beam with a wavelength of $355 \mathrm{~nm}$ ), although the quality of the components produced is still an issue as well as the efficiency to the actual production. Fabrication of meso- and micro-structured devices by direct-write deposition and laser processing of dry fine powders was also attempted [34] which is also seen to be an effective way to fabricate $3 \mathrm{D}$ structures with heterogeneous material compositions. The direct-write deposition system is able to produce a " $100 \mu \mathrm{m}$ minimum attainable feature size for device footprints ranging from sub-millimeter to a few centimeters" on a movable substrate. The prototype devices produced included micro-battery, inter-digitated capacitor, fractal antenna, Swiss-roll micro-combustor, and functionally graded polymeric bio-implants. By combining an electricchemical method and an etching method, a new manufacturing technique, so-called Efab manufacturing (a system developed by MEMGen, USA) has been developed [35]. The method adds layers from 2 to 20 microns thickness and is able to create 3D metallic features with support of the sacrificial material, which is late, etched away. The method may be limited to the deposition of connectors, and the process may also be slow. SDM combining micro-casting with other intermediate processing operations (CNC machining and shot peening) was also attempted to create metallic parts [36]. The better product quality could be achieved with proper control of interlayer metallurgical bonding (through substrate re-melting) and the cooling rates of both the substrate and the deposited material. Another good example of fabricating complex metallic micro-structures is to use lithography and etching techniques to make sacrificial silicon moulds. The multiple silicon layers are stacked and the metallic glass is then forced into the cavities under heat and pressure in an open air environment. Such an approach could also be a solution for low cost manufacturing [37]. The inkjet technology offers a prospect for reliable and low cost manufacturing of Flat Panel Display (FPD), compared to other conventional processes, such as a inkjet printing method for colour filters $(\mathrm{C} / \mathrm{F})$ in LCD or RGB patterning in OLED which offers potential for the mass production of enlarged-display panel with a low cost [38].

Assembly/Packaging: Basic processes for micro assembly and packaging include mechanical placement/insertion/pressing, micro-welding; resistance/laser/vacuum soldering, microcasting/moulding, bonding; gluing, etc. Interconnection and packaging solutions (e.g. 3D-moulding of interconnect devices) are a key technology for connecting micro systems to the macro world. 
Assembly/packaging gains more importance with the growth of complexity and miniaturisation of the products and systems. Although significant progress has been made in the manufacture of individual micro-components/parts, as well as MEMS, there is still a significant amount of manual work involved in assembly/packaging of the micro-products and systems. Assembly of individual technical components to hybrid micro-systems is a bottleneck to large scale production [39], which is evident especially in the areas of heterogeneous assembly, online-inspection and quality control. Integration of micro- and nano-devices through assembly is still a new area of challenges. A method for achieving electrical and mechanical interconnects for use in heterogeneous integration was combining metal reflow and a self-aligned, 3-D micro-assembly [40], which allows for the batch processing of a large number of heterogeneous devices into one system without sacrificing performance. Micro assembly injection moulding gives another option for joining plastics and some inlay part such as fibre reinforced needle and other elements [41]. The use of lasers for welding has exhibited tremendous growth over the last decade for improving efficiency and reducing costs in a broad range of industries for the manufacture of both macro and micro components [16] [42]. Efforts are continually being made for better understanding processes and controlling key parameters for better quality and efficiency. Online-inspection on joint quality is still not effective enough to what actually required by industry. For some micro-devices assembly, there is almost no efficient online-inspection-system available for industry to use, and therefore, quality control is extremely difficult. Another key issue for both MEMS- and none MEMS-based manufacturing is need of effective and efficient gripping techniques/systems and corresponding manipulation strategies/means for micro-assembly [43]. More on this issue will be dealt with in a late section of this paper.

\subsection{Process Chains and Hybrid Processes}

Presently significant efforts in micro-manufacturing development are focused on scaling down of the conventional processes and equipment to meet the requirements of manufacturing smallsizes/features, which sees that seeking higher precision and seeking better solutions to the handling of the small parts/objects result in significant cost. This is especially the case where the conventional macro-size-component-production methods and processes are to be transformed into that for the manufacturing of micro-products.

The trend of the current development is still dominated by separated development of individual methods and technologies [44-47]. For example, various processes are available for the manufacture of micro-channels each of which has its own limits to the materials and processes capability as well 
as applicability to mass production [45]. The same is for the manufacture of fuel cells: Various none-MEMS micro-fabrication techniques such as electrical discharge, electrochemical, laser, turning and milling can be used to make fuel cells [46].

New processes need to be developed to address the need of merging merits of two types of manufacturing methods, i.e. mass-production capability of conventional manufacturing methods (manufacture of the macro/miniature products) and capability of manufacturing the products at micro/nano-scales (such as MEMS based manufacturing methods). The first has difficulty to go down further in the sizes while the latter has relatively low efficiency, compared to that for largescale production (such as mechanical cutting and plastic forming).

To-date, some process chains have been tried in order to develop better quality and efficiency to address needs of dealing with various materials, and/or sizes/features, etc. A typical example is to combine lithographic tooling and injection moulding technologies for mass-production of microcomponents [48] by which various materials such as polymers, metals and ceramics can be processed. The efforts have also been made to improve the efficiency and process scopes of both, well-established and newly emerged micro-fabrication techniques (mostly still laboratory based), with a view either to transforming them into volume-production processes or to further increasing the production efficiency. Alternative lithography techniques that pattern photo-resist layers through selective thermo-chemical cross-linking have been tried to speed up the processes with extra heating [49]. An LIGA process could be improved by fabricating micro-moulds with direct femtosecond laser micro-machining [50]. The approach may lead to practical, cost-effective 3-D MEMS with various materials. Development of the buried features, following femtosecond laser micro machining, remains a challenge. Ultraprecision manufacturing of the self-assembled microsystems (UPSAMS) is another example of this kind of the development, which combines ultraprecision micromachining such as milling, turning, drilling, and grinding with sacrificial/structural multilayer manufacturing processes to produce self-assembled, 3D micro-systems and associated meso-scale interfaces from a variety of materials for MEMS applications. With this process, a new class of microsystems which is highly three dimensional, precisely machined, and automatically assembled, could be developed [51]. Rapid fabrication of micro-components may also be effected with combination of the UV-laser assisted prototyping, laser micro-machining of the mould inserts and replication via photo-moulding [52] which deals with materials such as polymers and composites. Development of the mould inserts made of polymers was performed via UV laser ablation (a promising method for the rapid manufacturing of micro-components). Another example of using combined techniques was equipment development and applications of the pulsed laser for 
micro-machining of large-area polymer substrates with micro-structures, which involve rapid prototyping, bow-tie scanning, synchronised image scanning (mask projection technique), etc. (some of these are associated with the EU FLAME project). The applications included flat panel display, solar panel, super-long inkjet printer nozzles, micro-lenses, diffusing structures fabrication, etc. [53-54].

Development of hybrid processes seem now another focus for micro/nano-manufacturing-related research the aim of which is to take advantages of the merits of some specific methods/processes while the associated disadvantages could be reduced or eliminated. Micro-EDM and Laser assembly were combined to fabricate 3D metal microstructures [55]. The system uses a micro-EDM process to fabricate micro-parts and Nd-YAG laser welding to assemble these micro-parts. By such a combination, increased numbers of the patterns, higher aspect ratios and higher joint strength of the microstructures can be achieved. Another merit is reduction or elimination of the number of post-assembly operations which may involve various efforts in handling and high-precision positioning. A new technology based on laser transmission welding combined with a photolithographic mask technique enables assembly of plastic microfluidic devices, MOEMS and microarrays requiring high positioning and welding accuracy in the micrometer range [56]. The system created consists of a diode laser with a mask and an automated alignment function to generate micro welding seams with freely definable geometries. A fully automated mask alignment system with a resolution of less than or equal to $2 \mu \mathrm{m}$ and a precise, non-contact energy input allow a fast welding of micro structured plastic parts with high reproducibility and excellent welding quality, as reported in [56]. Combining the ECM and EDM, i.e. so called Hybrid ECM-EDM, is another example of improving material processing efficiency. In EDM, sparks are needed (dielectrics), while these are unwanted for ECM (electrolyte, short circuit). The sparks would be encouraged for combined ECM-EDM with appropriate control. The applications include drilling of small holes in hard alloys, wire-machining removal of metallurgical samples, manufacture of dies and moulds, etc. Other hybrid processes include Laser-ECM and ELID processes. Since no a single technology could be dominant, development of hybrid processes and technology will prevail in near future as a solution of reducing the gaps between the laboratory type of processes and real industrial production, as well as solution of enabling multi-length-scale-integration manufacturing with better efficiency. This is a field needing to be strengthened.

Although, to-date, multi-processes and multi-materials micro-manufacturing have been attempted, fundamental understanding of how these combinations will influence product-quality is obviously insufficient. This is evident due to lack of an organised research effort in addressing this issue. 
Concerning shape deposition manufacturing (SDM) with micro-casting, thermal models were used to study the issue of the localised re-melting of previously deposited material by newly deposited molten droplets to achieve metallurgical bonding [50]. Mechanical modelling provides insight into residual stress build-up during the part manufacture and into the residual-stress-driven debonding between deposited layers. A useful work dealt with the material issues for micro-manufacturing and specific treatment was given to the materials factors unique to micro-manufacturing and different from traditional manufacturing [57]. While focus has been heavily on the fundamentals of individual processes, materials and products, study of tribology at micro/nano-scales and microsurface engineering in general are also important for multi-materials and multi-processes manufacturing than that for single-material, single process manufacturing, due to more interfacial interactions existing. New theories and methodologies dealing with friction, wear, lubrication, at the micro/nano-scale are much needed. Many of the vital issues in the micro- and nano-manufacturing are related to nanoscale wear, nano-gap lubrication, manufacture and modification of low-energy surfaces, friction and adhesion between the interfaces, etc. [58]. There is also a need of establishing new micro/nano-lubrication concepts. Establishment of theoretical guidance for the design related to the above-mentioned issues would contribute greatly to the development of micro- and nanomanufacturing technology, multi-materials and multi-processes manufacturing in particular.

\subsection{Manufacturing Systems/Equipment}

Traditionally, micro-manufacturing (non-MEMS manufacturing) was effected with large scale equipment, such as that for micro-mechanical-machining, micro-EDM and micro-metal-forming. To perform micro-manufacturing tasks with the equipment, significant efforts have been made to improve the precision of mechanical structures, to compensate for any mechanical and thermal errors, as well as to increase the functionality, resolution and reliability for online geometrical inspection. The cost paid for achieving these has been very high, while the resulting equipment is too expensive, which actually limits their applications to industry. The state-of-the-art large-scale equipment is not reviewed in this paper - miniature machinery/manufacturing systems is a focus.

\subsubsection{Miniature Manufacturing Systems / Micro-factory}

During the last 15 years bench-top machines or so-called miniature manufacturing systems have been gradually developed and introduced to industry. The development of such machines/systems has attracted a lot of interest from research organisations and industries. Various machine- and system-concepts are being explored. A main consideration is that conventional facilities for 
manufacturing miniature/micro-products are not compatible, in sizes, to the products to be made in miniature/micro-manufacturing. Therefore, it is necessary to reduce the scale of the equipment which could, in turn, reduce the energy-consumption and material requirements, reduce pollution, create a more user-friendly production environment, reduce equipment-cost, etc. At the same time, as the scales of the machinery and auxiliary equipment are reduced, the mass of the mechanical parts could be reduced dramatically and, as a result, the speed of the manufacturing tools could be increased, which could result in increase of the production rates, as the developers would expect. Another advantageous feature often mentioned is that the force/energy-loop and the control loops are significantly short for small machinery, therefore, the precision of the machinery could be increased comprehensively. These are points worthy being considered in micro-manufacturing equipment development.

The researchers in the Mechanical Engineering Laboratory, Ministry of Trade and Industry, Japan, were probably first group that proposed the micro-factory concept [59-61], in the early 1990s. The concept was to build a desktop miniature-system (factory) consisting of several machine tools plus a manipulator. To enable this, several miniature machine-tools were developed. The prototyped micro-factory was able to machine a number of small parts and assemble them into a miniature ball bearing [60]. This prototype-system explored the potential to build a micro-factory with real functional capabilities. The development similar to the prototype-system reported stimulated a lot of the interest in this area. During the last fifteen years several demonstration miniature/micromanufacturing systems have been developed [62-80]. A review on micro-factory for micromanufacturing applications was presented in the literature [20].

\subsubsection{Multiple-Process Equipment}

Majority of the equipment/device developed in a micro-factory or a miniature manufacturing system may not be classified as multi-process equipment/device since it may still be a standalone machine which deals with a particular process.

Development of the multi-process equipment is seen to be a solution for the minimisation of the number of the handlings in assembly and transport of micro-components, also for the reduction of the positioning errors of both tools and products. The idea has received very positive response in Asia, and typical development in this region includes the multifunctional micro-machining equipment developed in one of Chinese universities, which is able to perform several micromachining on the same machine-tool [81]. The equipment can perform micro-electro-discharge- 
machining, micro-electrochemical-machining, micro-ultrasonic-machining as well as their combinations. Using micro-EDM, micro-rods with diameters of less than $5 \mu \mathrm{m}$ were ground on block electrodes, and micro-holes and 3D microstructures were also obtained. Shaped holes were machined with a combination of micro-EDM and micro-USM. Another, similar multifunctional micro-machining system was developed in Ibaraki University, which is capable of micro-milling, turning, grinding, buffing, polishing, EDM, ECM, laser machining and their combinations [82]. The applications include fabrication of moulds for micro-lens. A recent development undertaken in National Taiwan University is a multi-function high-precision tabletop CNC machine. With this machine, the machining processes such as micro-high-speed-milling and micro-EDM (die-sinking and wire EDM) can be performed on the same machine without need of unloading, reloading and readjusting the workpiece for the subsequent operations. The system is also equipped with an inprocess workpiece/features geometrical measurement system [83]. The micro-electrodes as small as $8 \mu \mathrm{m}$ in diameter and the diameter/slenderness ratios as high as 100 could be achieved. Similar development is also seen in Singapore [84]. A multi-process miniature machine-tool has been developed at the National University of Singapore, which includes processes such as Micro-EDM, Micro-ECM, Micro-turning, drilling, and milling, as well as Electrolytic in-process dressing (ELID) grinding and single point diamond tool cutting. Another, interesting development which targeted low-cost equipment is an 5 axis milling-machine for the machining of micro-parts [85]. The machine was mainly composed of commercially available micro-stages, an air-spindle and PCbased control board. The machine was used for machining micro-walls, micro-columns and microblades. Although this development did not involve multiple processes, it explored an interesting concept that targets low cost equipment.

\subsubsection{Supporting Technologies/Devices/Systems for Micro-Manufacturing}

Considering handling at micro-scales, factors such as gravity cannot be considered as a main force applied to the parts to be handled. Unwanted surface forces such as van der Waals, electrostatic and surface tension forces are dominant at such scales. The pick-and-place problem is difficult to overcome in micro-world because adhesive forces must be taken into account. In micro handling the joint backlash and the structural vibration due to link flexibility must be controlled at the level of microns [86]. Higher care on manipulation and cleanliness are also required.

Challenges to micro-handling may have been well understood, and a key challenge may be that when handling is required to match the high production-rates to be deployed with some miniature/micro-manufacturing machines, which is far more difficult to achieve, compared to that 
in normal assembly/packaging of micro-electronics products.

Sensor systems play an important role in many fields of manufacturing. Their applications in micromanufacturing such as that in equipment and that for online inspection, require high levels of accuracy/resolution of the sensors. Data processing near the sensors, extracting more information from the directly sensed information by signal analysis, system miniaturisation, multi-sensors uses, etc. are the new demands [87]. Single-function transducers are now not enough to meet the needs, and the system-based sensors as system components are being introduced: systems containing both sensors, actuators and electronics, are being sought.

Since micro-manufacturing technologies for production are still being developed, lack of the standardisation and knowledge/experience in broad bases prevents their further applications. Quality assurance plays an even more important role in order to "efficiently support the transition of micro production processes from non-robust to stable processes" [88]. Quality assurance faces particular challenges in micro-production - some common quality methods would be difficult or even impossible to be applied/implemented. A need of the development of technologies and systems for efficient dimensional metrology at different length-scales and effectively integrating them is evident. As critical dimensions are scaled down and geometrical complexity of the objects increases, currently available technologies and systems may not be able to meet development needs. "New measuring principles and instrumentation, tolerancing rules and procedures as well as traceability and calibration, etc. will have to be developed" [89]. There are no specific tolerance guidelines for general tolerances for the newly emerged micro-manufacturing processes, and these currently largely rely on experience, which is normally not statistically established in a factory-site and/or has not been approached in a systematic way [90]. 3D measurement technology that would enable fast, accurate measurement of solid shapes in the sub-microns and even sub-nanometres region is essential for micro-manufacturing tasks [91]. Concerning surface inspection methods and performance of non-contact profilers, there is no single system which is able to offer all the features that a general purpose user would like simultaneously [92]. Providing all possible means available and integrating them into a flexible system to allow users to deal with different inspection requirements may be a solution to the problems.

\section{Technology Outcomes of MASMICRO}

MASMICRO was an EU FP6 Integrated Project which was focused on three themes: development of mass production processes based on micro-forming and micro-mechanical machining; 
development of miniature/bench-top equipment to bridge gaps between costly large-scale systems and micro-machines; and applications of ultra-precision techniques to improve the precision of previous miniature/micro-machine designs. These addressed some key-issues raised during a review of micro-manufacturing that is presented in the section 3 of this paper. Overall project-information and background considerations behind the project's objectives were given in the literatures [20, 2425] and other publications produced by the consortium's partners [25]. Overall, following results were produced:

(i) A whole set of the manufacturing facilities representing an integrated manufacturing facility for mass-manufacture of miniature/micro-products.

(ii) 3 Desk-top Micro-Forming-Machines, together with the completion of the key technologies and device for the machines - Micro-bulk, Micro-sheet and Microhydroforming Machines, as well as industry-version machine designs;

(iii) A Bench-top Micro/nano-machining machine-tool, together with the completion of the key technologies and device for the machine, as well as the industry-version machine design;

(iv) 5 sets of micro-forming-tools with new tool concepts (flexible bulk, sheet and hydroforming tools, intelligent and piezo-actuator-assisted forming tools);

(v) A series of new techniques and new/improved device for non-traditional manufacturing for volume-micro-production (Laser-equipment, Laser-forming, Photo-chemicalmachining and forming, and Micro-EDM), and integration of these into MASMICRO process chains;

(vi) The systems respectively for handling, assembly, testing and inspection (hardware and software) that sever for the Masmicro manufacturing processes and equipment;

(vii) A prototype Knowledge-Based Decision-Support System (software), A prototype Design Advisory Assessment System (software) and a Micro-Mechanics Analysis System (software) for the design, analysis and planning of miniature/micro-products and micro-manufacturing processes;

(viii) A set of novel micro/nano-materials and in-situ testing device/procedures for micro/nano-manufacturing applications.

By the end of September 2008, 48 exploitable results in total had been produced, some of these having already been introduced to industry. All of the project's development together reflect a "lifecycle" concept of the development of miniature/micro-products, as indicated in Fig. 1. Industry may selectively choose one of the developed facilities according to their own interest. According to actual products to be manufactured, the MASMICRO consortium as a whole will be able to deliver 
a full, integrated system (Fig. 2), that includes all of the key development from the project, hence, an integrated solution to industry, including training programmes. The following are examples of the manufacturing facilities developed:

Led by the Institute of Product Development (IPU) of Denmark, a miniature press and flexible tool system has been developed for the forming of micro-bulk-products (Fig. 3). This was the first EU attempt to mass-manufacture miniature/micro-components via micro-forming [22, 93-94]. The press is driven by a linear servo motor and is capable of fast and accurate motion. The tool-system enables eight different bulk-forming processes to be carried out only by changing small portions of the tool-elements. Precision of the tool-system is crucial due to narrow tolerances of the dimensions of the micro-components to be formed, which requires the manufacture of die-cavities within the sub-millimeters range in diameter and within a few microns in geometrical accuracy. The tooldevelopment gained support from Pascoe Engineering, Scotland, Fraunhofer Institute Production System and Design Technology of Germany (IPK). The press and tool system were successfully tested with the forming of two demonstration products selected by Pinol A/S of Denmark.

A new micro-sheet-forming machine system (desk-top machine) has been developed at the University of Strathclyde [95-96], in collaboration with Pascoe Engineering of Scotland, Tekniker of Spain and other project partners. The machine is capable of a series of micro-sheet-forming processes for forming thin sheet-metal parts with thickness of below 100 microns. The machine has capability of up to 800-1000 strokes per minute, force capacity of $5 \mathrm{KN}$, and machine precision 2-5 microns, with modular and flexible set-up. The machine is equipped with a new, linear-motor driven, high-speed feeder, a novel part-carrying system, and a force-displacement monitoring system. With the tool systems developed in collaboration with Pascoe Engineering Ltd., Gammastamp SpA of Italy, IPK of Germany and Tekniker of Spain, different types of materials have been tested for demonstrators. An industry-version machine is being built at Tekniker of Spain, with support from Pascoe Engineering and University of Strathclyde.

The Institute of Production (IFP) of the University of Applied Science Cologne (ASC) leads the development of the 1st generation hydroforming machine for the forming of miniature/microtubular components [97-98]. Hydorforming processes have been employed successfully in industry for producing products predominantly relating to lightweight automotive components. The massproduction of such components at present is, however, limited largely to the parts with crosssections of above about $20 \mathrm{~mm}$ in width. There was a lack of experience in the hydroforming of tubular, miniature/micro-parts. A machine system has been developed for the forming of miniature 
tubes with diameters down to $0.8 \mathrm{~mm}$ and thickness down to 20 microns. To assist in the deformation of miniature tubes, a laser system for localised heating is incorporated into the forming process. The applications of the system will significantly extend micro-manufacturing capabilities, especially manufacture of hollow sectioned parts, such as that used in micro-housing, fluidic devices, light-weight structures in micro-mechanical devices, etc. which has not been achieved before. The approved manufacturing capabilities may also fundamentally change the way in which some micro-products/device are currently being designed.

A bench-top, multiple-axis machine tool capable of machining intricate 3D geometries in components, with nano-scale tolerances, has been developed, led by the Brunel University and Ultra-Precision Motion Ltd. of the UK [99-100]. The associated series development includes an air bearing slideway and a rotary table with improved damping capacity (Patent Application: GB 0505798.9) and an ultra-high speed air bearing spindle (Loadpoint Ltd./Ultra-Precision Motion Ltd. of the UK), a piezo-driven fast tool servo system and Piezoelectric actuation unit for vibration assisted machining (CEDRAT Technologies S.A. of France), new micro diamond tools (Contour Fine Tooling Ltd of the UK), a robotic arm unit for micro-components/tools handling and management (Carinthian Tech Research AG of Austria), and a tool and spindle condition monitoring system (University of Patras of Greece).

MASMICRO Manufacturing Execution System (MES) was developed by Fraunhofer Institute IPA, Germany, to facilitate the integration of the manufacturing facilities developed within MASMICRO [101-102]. It was consequently built upon the concept of a service oriented architecture and implemented a number of additional measures to improve the agility of this class of systems, such as the integrated configuration management system covering all artifacts that determine the system's behaviour and the integration of real-time simulations to evaluate the configuration setup. In order to reduce the license costs for layered products, it made heavy use of proven internet concepts and technologies and thereby, reached a high level of scalability. Altogether, the system facilitates reduction of the time and budget required to adjust an MES to the requirements of a specific production environment.

The mobile-robot with a manipulator for micro-manufacturing system applications was another development by Robotnik of Spain, for facilitating the systems integration [103]. The system consists of a mobile platform and a robot arm. The platform can be controlled remotely via joystick or can work autonomously via laser sensor and beacons. It has also a laser range finder for obstacle avoidance. The robot arm is a 4 DOF Scara robot with a portable weight of up to $5 \mathrm{Kg}$ and an 
accuracy of $0.01 \mathrm{~mm}$. This robot arm can be upgraded with a camera to perform difficult tasks or to improve the final accuracy. The whole system is powered by two $50 \mathrm{Ah}$ batteries, and its final velocity is software restricted to $1 \mathrm{~m} / \mathrm{s}$.

The customized laser system for micro-material processing was another result from MASMICRO (by Latronics of Germany) [103]. Software controlled modular laser system based on a 50 Watt CW-Ytterbium fiber-laser. Material processing such as laser assisted Micro-forming and further application of 3D-micro-material processing were performed with a spatial resolution of $10 \mu \mathrm{m}$. Additional axes of rotation and translation can be implemented and synchronised with the "master software'. In order to avoid thermal drift of the scanner, an optical auto-calibration can be started at fixed time periods in order to achieve very accurate long term stability and reproducibility of the positioning of the focal point. These properties make the system suitable for accurate 'non-stop' processing of micro-components in an industrial production line.

Fast tool servo SPT400MML (developed by Cedrat Technologies SA of France) uses the patented Amplified Piezo Actuator from CEDRAT to achieve a fast motion of a diamond tool to machine free forms [103]. It includes an eddy current proximity sensor to increase the accuracy of the actuator. It is driven by a standard LA75C drive and controlled with the real time UC75 platform. The closed loop is performed at a high sampling rate and realizes the following tasks: closed loop between the SPT and the proximity sensor, and monitoring of the different variables of the SPT. The SPT400MML is compatible with specific diamond tools from Contour Fine Tooling Ltd. of the UK, with light shank of $6.35 \mathrm{~mm}$ square cross section. The preliminary performances are: Stroke up to $400 \mu \mathrm{m}$, bandwidth up to $450 \mathrm{~Hz}$ with a first resonant frequency above $600 \mathrm{~Hz}$, force capability up to $10 \mathrm{~N}$.

An inter-machine material handling system for handling micro-parts and for manufacturing integration was developed by Polytechnic University of Valencia of Spain [103], for which a conveyor belt system able to fit into a linear pick-and-place micro-manufacturing plant was developed. The system is composed of a central controller and several modules. Each module contains a programmable logic controller (PLC), some cassettes, conveyor segments, transfer units and handling devices. The micro-part sorting machine is another main part of this handling system. The machine is able to arrange the micro-parts into the cells of the standard carrier. An empty carrier is fixed on an $\mathrm{X}-\mathrm{Y}$ table. It moves the carrier under a micro-part feeder subsystem to ensure to accurately position the carrier/cells. To control the micro-parts flow, the feeding system is incorporated with a vibration principle and a vision feedback mechanism. 
An inspection system has been developed for micro-scale inspection of rotary micro-parts by Carinthian Tech Research AG of Austria [103]. With the system geometrical and surface features can be evaluated with a resolution of $5 \mu \mathrm{m}$. The parts are rotated under a line-scan camera. The acquired images are analysed with specific pattern recognition algorithms. The previously trained geometrical features are compared to allowable geometrical tolerances. The user receives a detailed file of the inspected data and feature errors, if occurred. Another inspection system is the "Optical Coherence Tomography (OCT) system", developed by Upper Austrian Research GmbH. It was developed as a contactless and non-destructive investigation tool of structures at the micron scales. 3D data from the interior of materials and micro-products can be acquired, as well as surface topographies. The acquisition time for an image with the size of one megapixel is only $36 \mathrm{~ms}$. The system can be used as a module for the stent inspection system, in order to measure the thickness of coating layers on medical stents, or can be operated as a stand-alone system for microstructure investigations.

A series of In-situ micro-material testing procedures and nano-manipulation set-ups for the testing of micro/nano-materials within SEM have been developed at the Swiss Federal Laboratories for Materials Testing and Research (EMPA) [104-106] and served for the project research, which increased the capability and flexibility of the testing of miniature/micro/nano materials with SEM. The development gave the project an enabling technology and device to test the materials at smaller scales with high accuracy which had not been achieved before. One of the advantages is capability of capturing micro/nano-materials crack and instability development (subject to the upsetting/compression) during in-situ tests of micro/nano-structures or surface features.

Other outcomes included micro- and nano-materials developed respectively by BPE International and Swedish Institute for Fibre and Polymer Research; Surface coating techniques for micro-tools developed by Centro de Ingenieria Avanzada de Superficies of Spain; Laser-assisted microstamping and roll-to-roll micro-hot-embossing techniques and tool designs developed by Fraunhofer Institute Laser Technology; New micro-EDM techniques developed by Fraunhofer Institute Production System and Design Technology; Micro- and precision-machinery testing algorithm and software system by MASMEC s.r.l. of Italy; Micro-mechanics analysis system developed by the University of Birmingham, etc. [103]

Over the project period (2004-2008), the MASMICRO project produced over 130 technical articles, this special issue being a collection of the latest technical papers produced by the project partners, 
which cover some of the scientific research and technological development described above that have not been published before.

\section{Conclusions and Remarks}

Micro-manufacturing research during last 10 years has been very intensive world-wide from which, significant results have been produced. Fundamentally, much better understanding of materials, processes and equipment has been achieved. Effort in converting manufacturing concepts to the lab processes, and further transforming these to volume production, has generated various, promising results towards industrial applications. More miniature/desktop manufacturing machines have now been marketed or to be marketed soon, and competition in this front will be very intensive within next few years.

To generate more significant impact onto the industry, economy and people's life in general, micromanufacturing will have to be better linked to macro-manufacturing and nano-manufacturing. Micro-manufacturing research and technological development should not be focused on "small things" only, but it also should serve as a vehicle to drive traditional manufacturing towards better quality and efficiency by providing better know-how on materials, processes, tool-design and fabrication and manufacturing precision, with more assured handling and control, and more reliable and efficient measurement and inspection, as well as adding more functionalities to existing products. In this sense, micro-manufacturing should have a broader definition from which traditional, large industries could sense more relevant factors. Similarly, standardisation of the materials, product design, manufacturing methods, processes and facility designs, will have to speed up, with joint effort, which may involve all parties in the micro-/nano-manufacturing chains and business. Further reducing overall cost of micro-manufacturing, especially cost of tools and equipment, is crucial for industrial applications. Currently, some of the expensive equipment serves mainly for research purposes. The research and technological development should also explore more on "add-on facilities" to enable existing industry to gradually transform/expand its business to/into micro-manufacturing without taking significant risks. Considering that many processes could be used for manufacturing micro-products for different geometries, materials and functionalities, while single-process equipment may only have limited applications and investment for manufacturing a single micro-product with such equipment may not be cost-justified, more effort should be made to develop length-scale integration manufacturing facilities, multiple-process equipment and hybrid manufacturing process equipment. To reduce business risks, innovative 
business models also need to be introduced, including collaborative virtual enterprises, optimised supply chains, etc.

In the scientific research front, characterisation of the micro/nano-materials and interfaces needs further effort. Material databases with detailed information on various materials and their properties/interface properties including micro-structures and size-effects would be very useful for product innovation and process design. Multi-phase, multi-scale, and heterogeneous mechanics modelling need to be introduced directly to micro-manufacturing process and product design. Micro/nano-wear and damages/failures of micro-manufacturing-tools need to be studied more, and the knowledge generated should be transferred to the tool design and fabrication, especially surface treatment of the tools. More fundamental studies are also needed on interactions between the materials and handling-tools with a view to delivering better design for handling and assembly, including development of better handling methods for high-rate manufacturing. Online inspection matching high-rate micro-production is still a challenging topic for research, regarding a high level of resolution, accuracy and speed that are to be met together.

\section{Acknowledgement}

The support from the European Commission for conducting research in the "Integration of Manufacturing Systems for Mass-manufacture of Miniature/Micro-Products (MASMICRO)" (NMP2-CT-2004-500095) (www.masmicro.net) is acknowledged. Contributions from all MASMICRO consortium partners to the project's achievements are particularly acknowledged. The authors especially would like to thank Prof. Neal Juster, Chair of the MASMICRO project, Vice-

Principal of the University of Glasgow (formerly Pro-Vice-Principal of the University of Strathclyde), and Mr. Hans Hartmann Pedersen, Project Officer of the European Commission, for their encouragement, guidance and support to the project, and Prof. Frank Travis for his careful check of the manuscripts of this special issue.

\section{References}

[1] EU MINAM Newsletters, Prepared by the University of Strathclyde, through the EU Coordination Action Project Micro-Sapient, 2006-2009.

[2] http://cordis.europa.eu/fp6/projects.htm

[3] http://cordis.europa.eu/data/PROJ_FP5/ 
[4] World Technology Evaluation Center (WTEC, USA), Report on Micro-Manufacturing, 2004.

[5] L. Alting, F. Kimura, H.N. Hansen and G. Bissacco, "Micro Engineering”, CIRP Annals Manufacturing Technology, v 52, n 2, 2003, pp. 635-657.

[6] S.Y. Liang, "Mechanical machining and metrology at micro/nano scale", Proc. of SPIE - The International Society for Optical Engineering, v 6280 I, Third International Symposium on Precision Mechanical Measurements, 2006, pp. 628002.

[7] X. Luo, K. Cheng, D. Webb and F. Wardle, "Design of ultraprecision machine tools with applications to manufacture of miniature and micro components", J. of Materials Processing Technology, v 167, n 2-3, Aug 30, 2005, pp. 515-528.

[8] K. Najafi, "Micromachined micro systems: Miniaturization beyond microelectronics", IEEE Symposium on VLSI Circuits, Digest of Technical Papers, June 2000, Honolulu, HI, USA, pp. 6-13.

[9] G.M. Robinson and M.J. Jackson, "A review of micro and nanomachining from a materials perspective", J. of Materials Processing Technology, v 167, n 2-3, 2005, pp. 316-337.

[10] K.P. Rajurkar, G. Levy, A. Malshe, M.M. Sundaram, J. McGeough, X. Hu, R. Resnick and A. DeSilva, "Micro and Nano Machining by Electro-Physical and Chemical Processes", CIRP Annals - Manufacturing Technology, v 55, n 2, 2006, pp. 643-666.

[11] E. Uhlmann, P. Sascha and K. Schauer, "Micro milling of sintered tungsten-copper composite materials”, J. of Mater. Proc. Technol., v 116, 2001, pp.39-43.

[12] E. Uhlmann, S. Piltz and U. Doll, "Machining of micro/miniature dies and moulds by electrical discharge machining-Recent development”, J. of Mater. Proc. Technol., v 167, n 2-3, 2005, pp. 488-493.

[13] D.T. Pham, S.S. Dimov, S. Bigot, A. Ivanov, K. Popov, 'Micro-EDM - recent developments and research issues', J. of Mater. Proc. Technol., v 149, 2004, pp. 50-57.

[14] B. Bhattacharyya, J. Munda and M. Malapati, "Advancement in electrochemical micromachining”, Int. J. of Machine Tools and Manufacture, v 44, n 15, 2004, pp. 1577-1589.

[15] J.A. MacGeough, "Electrochemical Machining", Technical Presentation, University of Strathclyde, Glasgow, UK, March, 2009.

[16] A. Gillner, J. Holtkamp, et al. "Laser applications in microtechnology", J. of Materials Processing Technology, v 167, n 2-3, pp. 494-498.

[17] M. Xia and Y. Tu, "An investigation of femtosecond laser micromachining”, Proc. of 2005 International Conference on MEMS, NANO and Smart Systems, pp. 296-300.

[18] P. Bado, W. Clark and Ali Said, Micromachining Handbook, 2001, Clark-MXR, Inc. USA.

[19] Y. Li, J. Tian and Q. Sun, "Micro-fabrication by femtosecond laser pulses", Proc. of SPIE The International Society for Optical Engineering, v 6149, 2006, pp. 61490X. 
[20] Y. Qin, "Micro-forming and miniature manufacturing systems - Development needs and perspectives", Keynote Paper (plenary address) of the 11th Int. Conf. of Metal Forming, Sept. 2006, Journal of Materials Processing Technology, v 177, n 1-3, 2006, pp. 8-18.

[21] M.Geiger, M.Kleiner, R.Eckstein, N.Tiesler and U.Engel, "Micro-forming", Annals of the CIRP Vol. 50/2/2001 pp. 445-462.

[22] M. Arentoft and N.A. Paldan, "Production equipment for manufacturing of micro metal components", Proc. of ESAFORM2006, April, Glas-gow, 2006, pp. 579-582.

[23] U. Engel and S. Geibdorfer, "Microforming technology - on the way to industrial application?", Proc. of the $1^{\text {st }}$ Int. Conf. on Micro-manufacturing, Urbana-Champaign, USA, Sept. 2006, pp. 21-30.

[24] Y. Qin, "Development of an integrated manufacturing facility for mass-manufacture of miniature/micro-products", Keynote Paper, Proc. of the 1st Int. Conf. on Micro-Manufacturing, Urbana-Champaign, USA, Sept. 2006, pp. 35-40.

[25] MASMICRO Project Web-site: http://www.masmicro.net/.

[26] A. Bayer, A. Gillner, P. Groche and R. Erhardt, "Laser-assisted forming of metallic microparts", Proc. of SPIE - The International Society for Optical Engineering, v 5063, Fourth International Symposium on Laser Precision Microfabrication, 2003, pp. 157-162.

[27] X. Peng, Y. Qin and R. Balendra, "Analysis of the laser-heating methods for micro-parts stamping applications", J. of Mater. Proc. Technol., v 150, n 1-2, 2004, pp. 84-91.

[28] X. Peng, Y. Qin and R. Balendra, "A numerical investigation to the strategies of the localised heating for micro-part stamping”, Int. J. of Mechanical Sciences, v 49, n 3, 2007, pp. 379-391.

[29] C.K. Malek and V. Saile, "Applications of LIGA technology to precision manufacturing of high-aspect-ratio micro-components and -systems: A review", Microelectronics Journal, v 35, n 2, February 2004, pp. 131-143.

[30] N.H. Loh, S.B. Tor, B.Y. Tay, Y. Murakoshi and R. Maeda, "Micro powder injection molding of metal microstructures", Materials Science Forum, v 426-432, n 5, 2003, pp. 4289-4294.

[31] J.A. MacGeough, M.C. Leu, K.P. Rajurkar, A.K.M. De Silva and Q. Liu, "Electroforming process and application to micro/macro manufacturing”, CIRP Annals - Manufacturing Technology, v 50, n 2, 2001, pp. 499-514.

[32] V. Kadekar, W. Fang and F. Liou, "Deposition Technologies for Micromanufacturing: a Review”, ASME Transactions, J. of Manufacturing Science and Engineering, Nov. 2004, v 126, pp. 787-795.

[33] X. C. Li, H. Choi and Y. Yang, "Micro rapid prototyping system for micro components", Thin Solid Films, v 420-421, Dec 2, 2002, pp. 515-523. 
[34] P. Kumar and S. Das, "Fabrication of meso- and micro-structured devices by direct-write deposition and laser processing of dry fine powders", 2004 ASME International Mechanical Engineering Congress and Exposition, pp. 519-524.

[35] Paul Dvorak, "Manufacturing macro and micro designs", Machine Design, Oct. 10, 2003, pp. 76-78.

[36] C.H. Amon, et al, "Shape deposition manufacturing with microcasting: Processing, thermal and mechanical issues", Journal of Manufact. Sci. and Engng., Trans. of the ASME, v 120, n 3 , Aug, 1998, pp. 656-665.

[37] J.A. Bardt, et al., "Precision molding of complex metallic micro-structures", Proc. Of the $1^{\text {st }}$ Int. Conf. on Micro-manufacturing, Champaign, IL, USA, Sept. 2007, pp. 274-279.

[38] B.H. Ryu and Y.M. Choi, "Application of inkjet technology in flat panel display", Proc. of Int. Meeting on Information Display, v 2, 2006, pp. 913-918.

[39] K. Najafi, "Micropackaging technologies for integrated microsystems: Applications to MEMS and MOEMS", Proc. of SPIE - The International Society for Optical Engineering, v 4982, 2003, pp. ix-xxvii

[40] T. Huang, et al. "3-D, self-aligned, micro-assembled, electrical interconnects for heterogeneous integration", Proc. of SPIE - The International Society for Optical Engineering, v 4981, 2003, pp. 189-201.

[41] W. Michaeli and D. Opfermann, "Micro assembly injection moulding", Microsystem Technologies, v 12, n 7, June, 2006, pp. 616-619.

[42] R.P. Martukanitz, "A critical review of laser beam welding”, Proceedings of SPIE - The International Society for Optical Engineering, v 5706, 2005, pp. 11-24.

[43] J. Cecil, D. Vasquez and D. Powell, "A review of gripping and manipulation techniques for micro-assembly applications”, Int. J. of Production Research, v 43, n 4, Feb 15, 2005, pp. 819828.

[44] A. Yabe, et al., "Road map of micro-engineering and nano-engineering from manufacturing and mechanical engineering viewpoints”, JSME International Journal, Series B: Fluids and Thermal Engineering, v 47, n 3, August, 2004, pp. 534-540.

[45] S. Ashman and S. G. Kandlikar, "A review of manufacturing processes for microchannel heat exchanger fabrication", Proceedings of the 4th International Conference on Nanochannels, Microchannels and Minichannels, ICNMM2006, 2006, pp. 855-860.

[46] P. Rajurkar, "Micro-fabrication techniques for fuel cell manufacturing", Proc. of the 1st European Fuel Cell Technology and Applications Conference 2005, pp. 207.

[47] K. Ehmann, and R. DeVor, “An international assessment of micro-manufacturing technology”, Advanced Materials and Processes, v 163, n 8, August, 2005, pp. 46. 
[48] D. F. Heaney, "Mass production of micro-components ultilising lithographic tooling and injection molding technologies. ", Proc. Of the $1^{\text {st }}$ Int. Conf. on Micro-manufacturing, Champaign, IL, USA, Sept. 2007, pp. 280-283.

[49] M. T. Hung, J. Kim and Y. S. Ju, "Exploration of thermolithography for micro- and nanomanufacturing”, Applied Physics Letters, v 88, n 12, Mar 20, 2006, pp. 123110.

[50] J. A. Palmer, et al., "Advancing three-dimensional MEMS by complimentary laser micro manufacturing", Proc. of SPIE - The International Society for Optical Engineering, v 6109, 2006, pp. 61090A.

[51] A. Sharon, et al., "Manufacturing of 3D microstructures using novel UPSAMS process (ultra precision manufacturing of self-assembled micro systems", Proc. of the IEEE Micro Electro Mechanical Systems (MEMS), 2003, pp. 542-545.

[52] W.Pfleging, "Rapid fabrication of microcomponents - UV-laser assisted prototyping, laser micro-machining of mold inserts and replication via photomolding", Microsystem Technologies, v 9, n 1-2, 2003, pp. 67-74.

[53] H.J. Booth, "Recent applications of pulsed lasers in advanced materials processing", Thin Solid Films, Vol. 453-454, 2003, pp. 450-457.

[54] //www.exitechinc.com/.

[55] C. L. Kuo, J. D. Huang and H.Y. Liang, "Fabrication of 3D Metal Microstructures Using a Hybrid Process of Micro-EDM and Laser Assembly”, Int. J. of Adv. Manufact. Technol., v 21, n 10-11, 2003, pp. 796-800.

[56] J.W. Chen, J. Zybko and J. Clements, "Diode laser bonding of planar MEMS, MOEMS, and microfluidic devices", Materials Research Society Symposium Proceedings, v 872, Micro- and Nanosystems - Materials and Devices, 2005, pp. 309-314.

[57] D.L. Bourell, "Materials issues in micro-manufacturing”, Proc. Processing and Fabrication of Advanced Materials XIV With Frontiers in Materials Science: Innovative Materials and Manufacturing Techniques, 2005, pp. 157-182.

[58] J. B. Luo, et al., "Challenges to tribology arisen from the development of micro- and nanomanufacturing technology", Mocaxue Xuebao/Tribology, v 25, n 3, May, 2005, pp. 283-288.

[59] http://www.mel.go.jp/

[60] N Mishima, K Ashida, T Tanikawa and H Maekawa, "Design of a microfactory", Proceedings of the ASME Design Engineering Technical Conference - 7th Design for Manufacturing Conference, Sep 29-Oct 2, Montreal, Que., Canada, v 3, 2002, pp. 103-110.

[61] Y Okazaki, N Mishima and K Ashida, "Microfactory and micro machine tools", presented in the 1st Korea-Japan Conference on Positioning Technology, Oct. 15-17, KIMM, Daejeon, Korea, 2002, pp. 1/6-6/6. 
[62] Masayuki Suda, Kazuyoshi furata, Toshihiko Sakuhara and Tatsuaki Akata, "The microfactory system ing electrochemical machining", Galvanotechnik, D-88348 Saulgau, 90. (9), 2000, pp. 2607-2609.

[63] Makoto Tanaka, "Development of desktop machining microfactory”, RIKEN Review, No. 34, April, 2001 - Focused on Advances on Micro-mechanical Fabrication Techniques, 2001, pp. 46-49.

[64] Tatsuaki Ataka, "The experimental microfactory system in Japanese National R\&D project", http://websrv2.tekes.fi/opencms/opencms/OhjelmaPortaali/Paattyneet/Presto/fi/Dokumenttiarki sto/Viestinta_ja_aktivointi/Seminaarit/Seminaari0601/

[65] Jean-Marc Breguet and Arvid Bergander, "Toward the personal factory", Proceedings of SPIE - The International Society for Optical Engineering, v 4568, 2001, pp. 293-303.

[66] N Mishima, "Design of a miniature manufacturing system for micro-fabrication", Proc. 10th ISPE International Conference on Concurrent Engineering, 2003, pp. 1129-1135.

[67] H Zhao, W Yuan and B Ma, "On the modeling of prototype system of the desktop microfactory", Journal of Mechanical Strength, v 23, n 4, Dec. 2001, pp. 495-499.

[68] http://www.atv-semapp.dk/ARR2005/ DanishMicroFactory1.pdf

[69] http://www.microned.nl/Documents/Microfactory.doc.

[70] M Asami, et al., "Development of a desktop micro injection molding machine", Key Engineering Materials, v 238-239, 2003, pp. 389-394.

[71] H Aoyama, F Iwata and A Sasaki, "Desktop flexible manufacturing system by movable miniature robots - miniature robots with micro tool and sensor", Proc. - IEEE International Conference on Robotics and Automation, 1995, pp. 660-665.

[72] H Aoyama, F Iwata and A Sasaki, "Miniature robots for a desktop flexible micro manufacturing system”, IEEE Control Systems Magazine, v 16 (1), Feb. 1996, pp. 6-12.

[73] E Kussul, T Baidyk, L Ruiz-Huerta, A Caballero-Ruiz, G Velasco and L Kasatkina, "Development of micromachine tool prototypes for microfactories", J. Micromechanics and Microengineering, n 12, 2002, pp. 795-812.

[74] T Kitahara, K Ashida, M Tanaka, Y Ishikawa, N Oyama and Y Nakazawa, "Microfactory and microlathe”, Proc. 1st Int. Workshop on Microfactories, Tsukuba, Japan, 7-9th Dec. 1998, pp. $1-8$.

[75] Ivano Beltrami, Cédric Joseph, Reymond Clavel, Jean-Philippe Bacher and Stefano Bottinelli, "Micro- and nanoelectric-discharge machining”, J. Mater. Proc. Technol., v 149, n 1-3, 2004, pp. 263-265. 
[76] S Wakuri, R Uenaka, N Nakajima and T Murakami, "Development of micro gripper for microfactory using two-way shape memory alloy", C Hen/Transactions Japan Society of Mechanical Engineers, Part C, v 68, n 4, April 2002, pp. 1231-1238.

[77] S Fatikow and K Santa, "Planning and control of a microassembly process in a flexible microrobot-based desktop station", Proceedings of SPIE - The International Society for Optical Engineering, v 3519, 1998, p 24-35.

[78] S Fatikow, R Munassypov and U Rembold, "Assembly planning and plan decomposition in an automated microrobot-based microassembly desktop station", Journal Intelligent Manufacturing, v 9, n 1, Feb. 1998, pp. 73-92.

[79] S Fatikow, Sergej, A Buerkle and J Seyfried, “Automatic control system of a microrobot-based microassembly station using computer vision", Proceedings of SPIE - The International Society for Optical Engineering, v 3834, 1999, pp. 11-22.

[80] T Gaugel, M Bengel and D Malthan, "Building a mini-assembly system from a technology construction kit”, Assembly Automation, v 24, n 1, 2004, pp. 43-48.

[81] B.X. Jia, et al., "Research on multifunctional micro machining equipment", Materials Science Forum, v 471-472, Advances in Materials Manufacturing Science and Technology, 2004, pp. $37-42$.

[82] L. Zhou, et al., "Development of a multifunctional micro-machining system and its applications”, Key Engineering Materials, v 238-239, 2003, pp. 3-8.

[83] Y. S. Liao, S. T. Chen and C. S. Lin, "A multi-function high precision tabletop CNC machine for making micro-parts developed in National Taiwan University", Proc. of the $1^{\text {st }}$ ICOMM, Sept. 2006, pp. 48-52.

[84] Y. Okazaki, N. Mishima and K. Ashida, "Microfactory - Concept, History and Development", ASME Transactions, J. of Manufacturing Science and Engineering, v 126, Nov. 2004, pp. 837844.

[85] Y.B. Bang, K.M. Lee and S. Oh, "5-axis micro milling machine for machining micro parts", Int. J. of Advanced Manufacturing Technology, v 25, n 9-10, May, 2005, pp. 888-894.

[86] A.J. Sanchez-Salmeron, R. Lopez-Tarazon, R. Guzman-Diana and C. Ricolfe-Viala, "Recent development in micro-handling systems for micro-manufacturing", Journal of Materials Processing Technology, v 167, n 2-3, Aug 30, 2005, pp. 499-507.

[87] P.R. Hauptmann, "Selected examples of intelligent (micro) sensor systems: State-of-the-art and tendencies", Measurement Science and Technology, v 17, n 3, Mar 1, 2006, pp. 459-466.

[88] J. Fleischer, G. Lanza, M. Schlipf and I. Behrens, "Quality assurance in micro production”, Microsystem Technologies, v 12, n 7, June, 2006, pp. 707-712. 
[89] H.N. Hansen, K. Carneiro, H. Haitjema and L. De Chiffre, "Dimensional Micro and Nano Metrology”, CIRP Annals - Manufacturing Technology, v 55, n 2, 2006, pp. 721-743.

[90] A. Albers, N. Burkardt, J. Marz, J. Oerding and M. Ohmer, "Concept of a micro gear tolerance management: What really happened!”, VDI Berichte, n 1904 I, 2005, pp. 959-981.

[91] H. Tsukahara, "Three-dimensional measurement technologies for advanced manufacturing", Fujitsu Scientific and Technical Journal, v 43, n 1, January, 2007, pp. 76-86.

[92] R. Artigas, F. Laguarta and C. Cadevall, "Dual-technology optical sensor head for 3D surface shape measurements on the micro and nano-scales", Proc. of SPIE - The International Society for Optical Engineering, v 5457, Optical Metrology in Production Engineering, 2004, pp. 168174.

[93] M. Arentoft, N. Paldan and R.S. Eriksen: "Cold forging of Industrial Micro Components", 39th ICFG plenary meeting, International Cold Forging Group, Korea Institute of Machinery and Materials, August 2006, Changwon, Korea, pp. 83-86.

[94] C.P. Withen, J.R. Marstrand, M. Arentoft, N.A. Paldan: "Flexible tool system for cold forging of micro components", First International Conference on Multi-Material Micro Manufacture, 29June-1 July 2005, Forschungszentrum Karlsruhe, Germany, Elsevier, pp. 143-146.

[95] Y. Qin, et al, "Development of a new machine system for the forming of micro-sheetproducts", Proc. of ESAFORM, Springer Paris, ISSN 1960-6214, DOI: 10.1007/s12289-0080098-9, April, 2008, pp. 1-4.

[96] A. Razali, Y. Qin, C. Harrison and A. Brockett, "Investigation of feeding devices and development of design considerations for a new feeder for micro-sheet-forming”, Int. J. of Nanomanufacturing, Vol. 3, No. 1/2, 2009, pp. 40-54.

[97] C. Hartl, J. Lungershausen, H. Biedermann and J. Conzen, J, "Study of hydroforming processes for the production of micro-components", Proc. of 1st Jubilee Scientific Conf. Manufacturing Engineering in Time of Information Society, Gdansk, 2006, pp.137-140.

[98] C. Hartl, J. Lungershausen, J. Eguia, G. Uriarte and F. Lopez Garcia, "Micro hydroforming process and machine system for miniature/micro products", Proc. of Int. Conf 7th euspen, Bremen, Vol. 2, 2007, pp. 69-72.

[99] Dehong Huo \&, Kai Cheng. "A dynamics-driven approach to precision machines design for micro-manufacturing and its implementation perspectives". Journal of Engineering Manufacture, IMechE Proc. Vol. 222, No. B1, 2008, pp.1-13.

[100] Stavropoulos, P., K. Salonitis, A. Stournaras, J. Pandremenos, J. Paralikas and G. Chryssolouris, "Advances and Challenges for tool Condition Monitoring in Micro-Milling", Proceedings of the IFAC Workshop on Manufacturing Modelling, Management and Control, Budapest, Hungary, November 2007, pp. 157-162. 
[101] R. Muckenhirn and M. Meier, “A minimal-invasive approach to configuration management supporting collaborative factory configuration scenarios”, J. of Intelligent Manufacturing, Vol. 19, No. 6, 2008, pp. 735-746.

[102] M. Meier, C. Fischmann and F. Böttinger, "Synergien nutzen : Wie die MES-Entwicklung von Werkzeugen der Logistikplanung profitieren kann. (English title: Utilizing synergies How the MES development benefits from logistics planning tools)", Wt Werkstattstechnik 98, 2008, Nr. 5, S. pp. 422-427.

[103] MASMICRO Consortium, "MASMICRO Demonstration Days", Dissemination Booklet, April, 2008.

[104] J. Michler, K. Wasmer, S. Meier, F. Oestlund, and K. Leifer, "Plastic deformation of gallium arsenide micropillars under uniaxial compression at room temperature”, Appl. Phys. Lett. 90, $043123,2007$.

[105] B. Moser, K. Wasmer, L. Barbieri, and J. Michler, "Strength and fracture of Si micropillars: A new scanning electron microscopy-based micro-compression test”, J. of Materials Research, Vol. 22, No. 4, 2007, pp. 1004-1011.

[106] L. Philippe, P. Schwaller, G. Bürki, and J. Michler, "A compression of microtensile and microcompression methods for studying plastic properties of nanocrystalline electrodeposited nickel at different length scales", J. of Materials Research, Vol. 23, No. 5, 2008, pp. 13831388. 


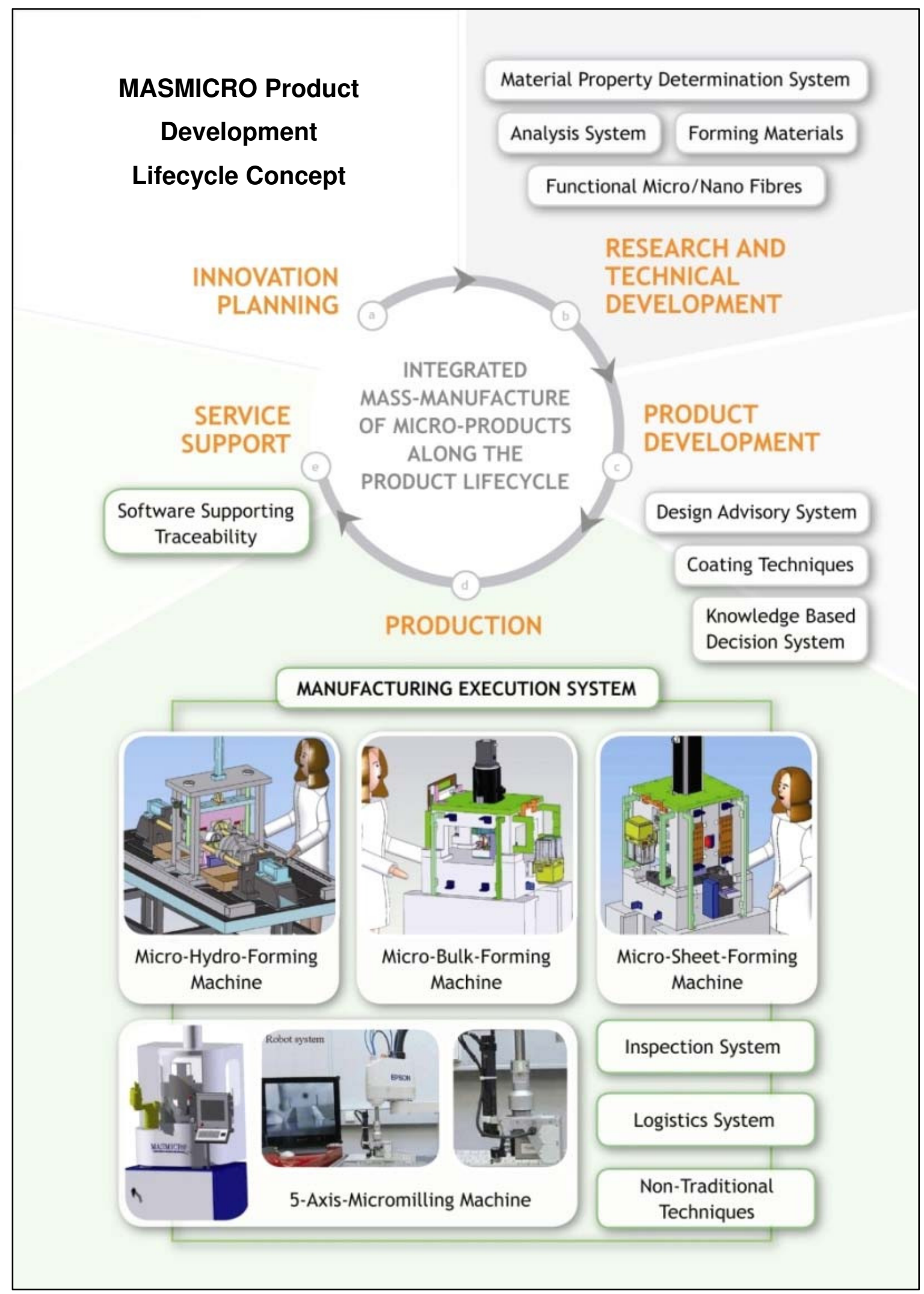

Fig. 1 MASMICRO lifecycle concept for the development of micro/miniature products (prepared by IPA) 


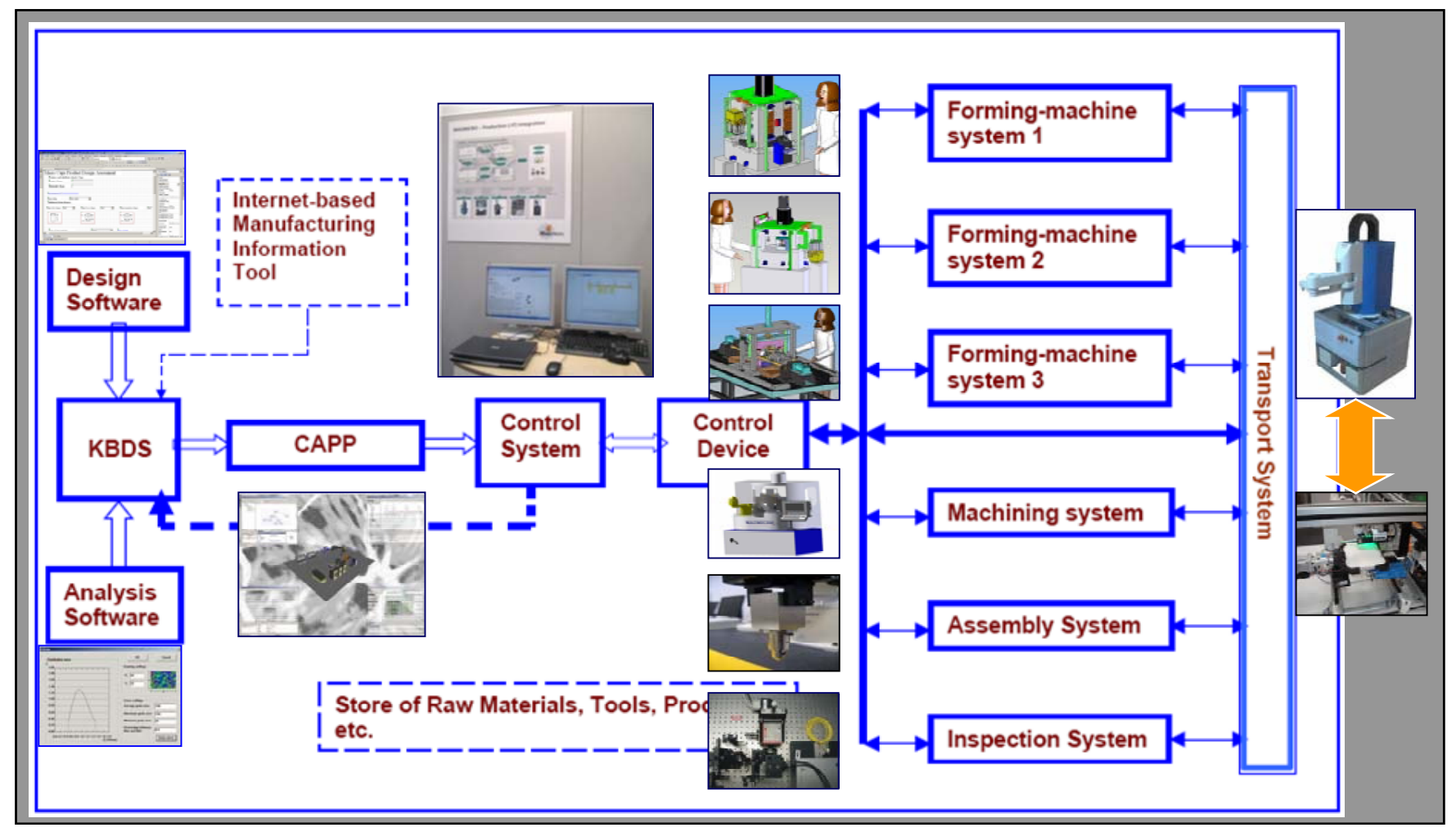

Fig. 2 Illustration of the MASMICRO Factory for Forming and Machining based MicroManufacturing (MASMICRO Consortium) 


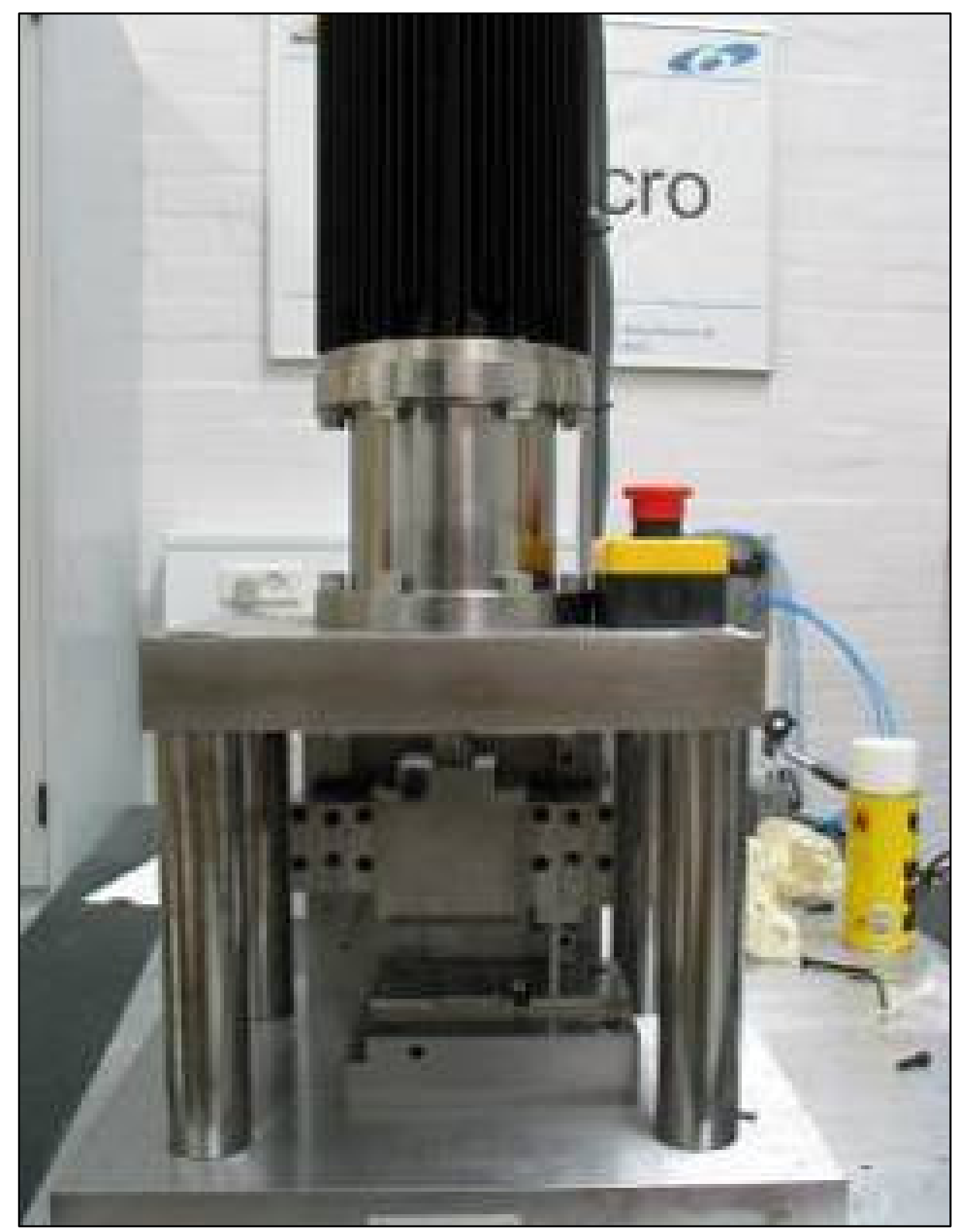

Fig. 3 The micro-bulk-forming machine system developed by IPU and partners 


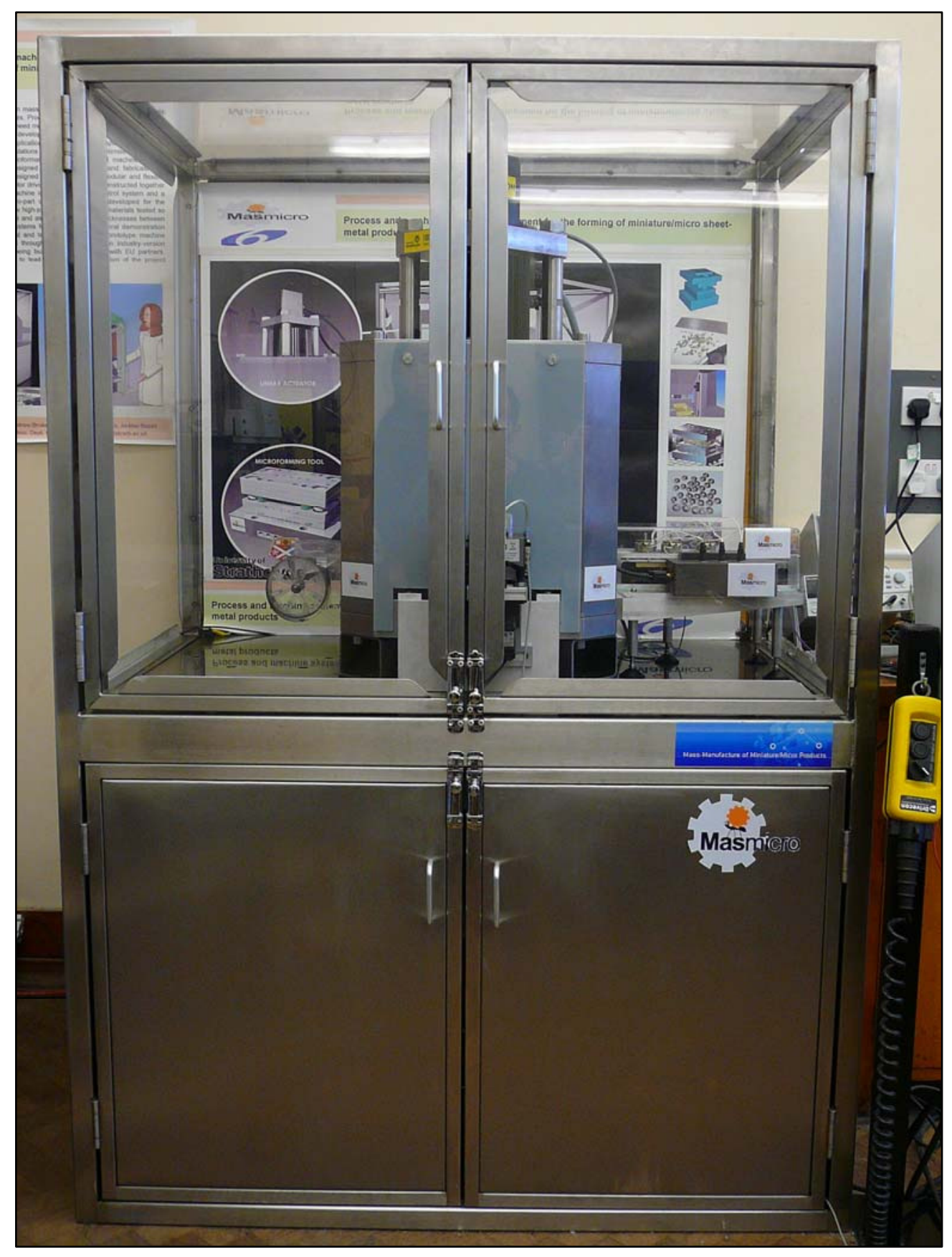

Fig. 4 The micro-sheet-forming machine system developed by the University of Strathclyde and partners 


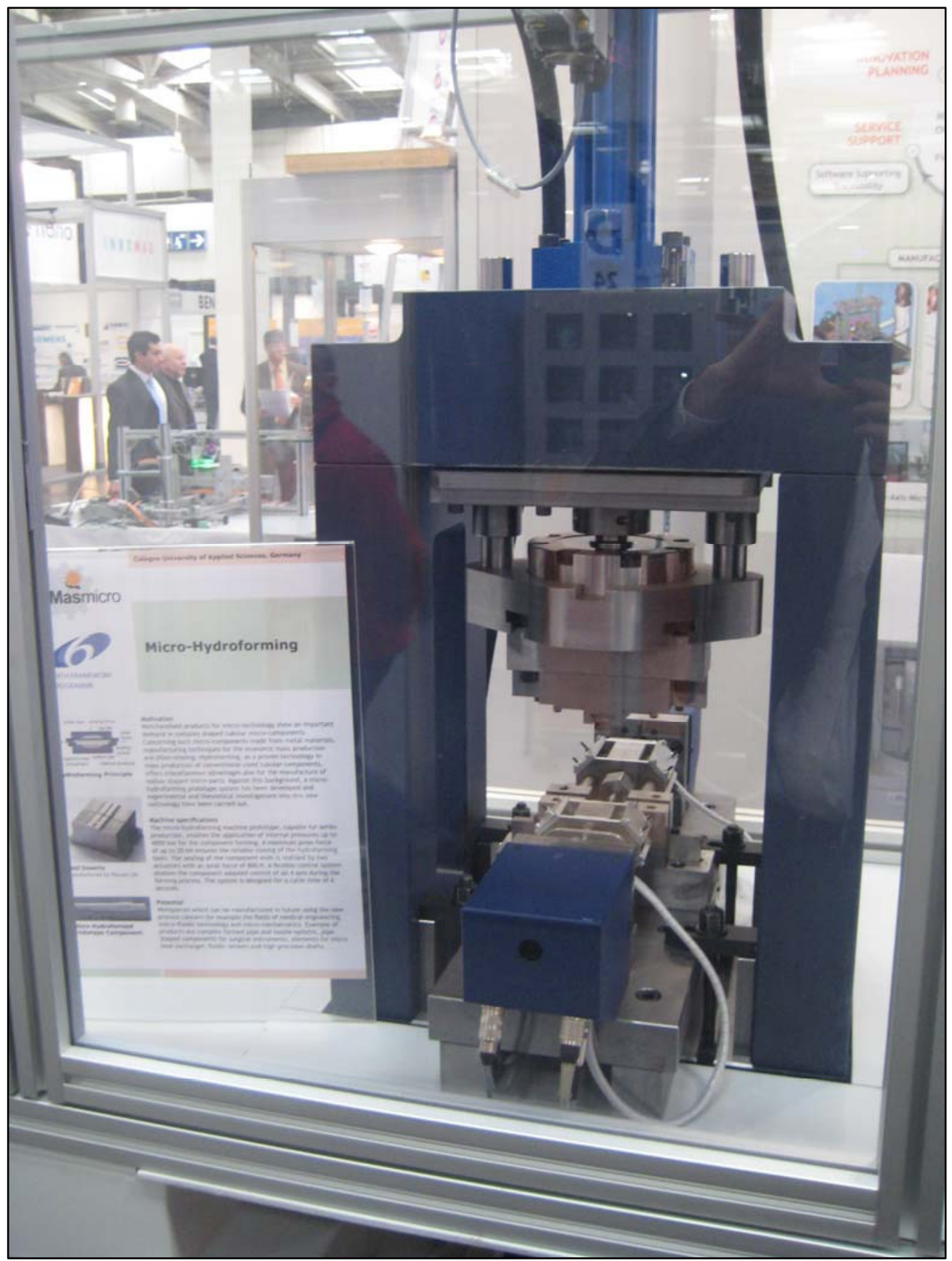

Fig. 5 The micro-hydro-forming machine system developed by the University of Applied Science Cologne and partners 


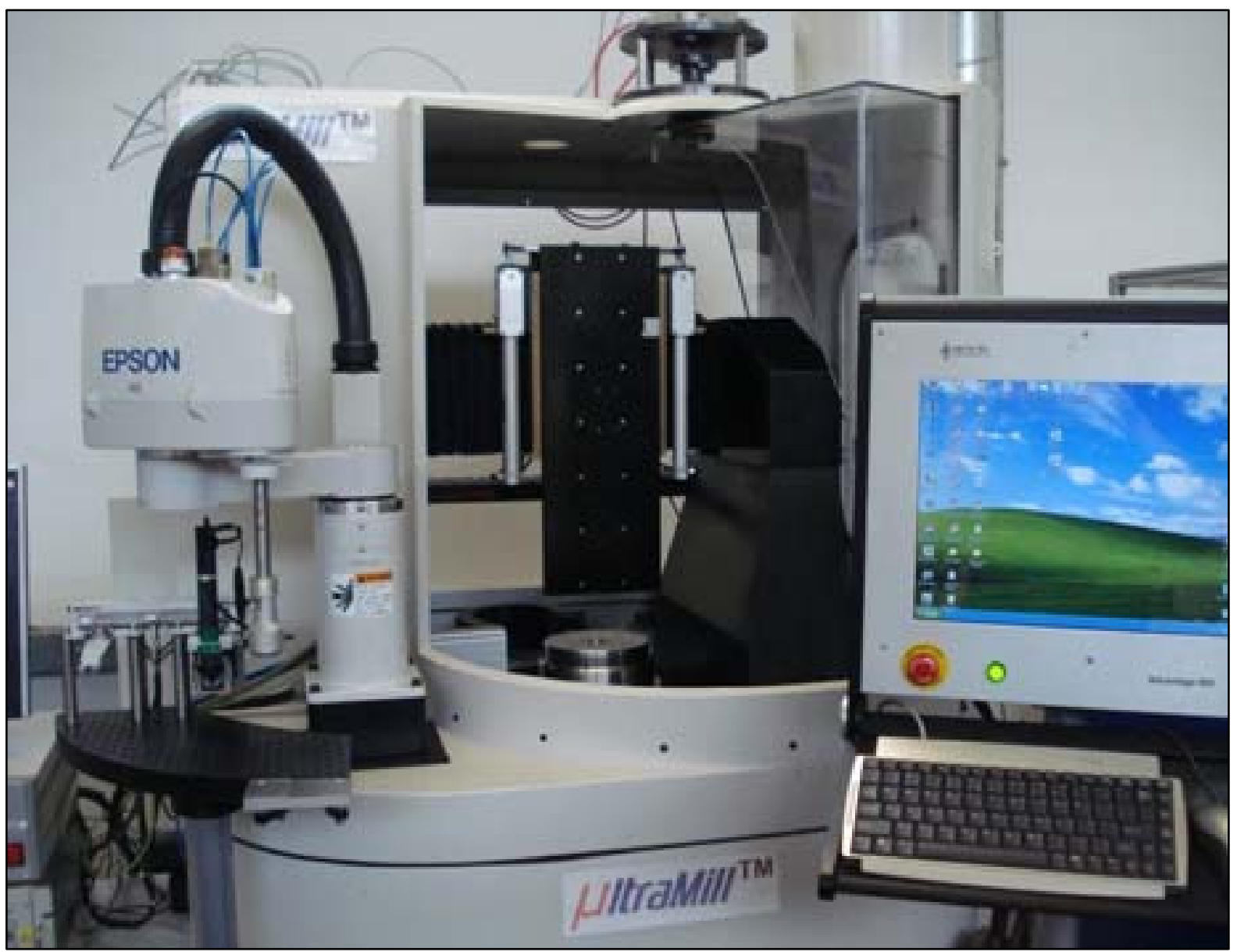

Fig. 6 The micro/nano-cutting machine-tool system developed by Brunel University and partners 